\title{
The effects of glass ionomer and flowable composite liners on the fracture resistance of open-sandwich class II restorations
}

\author{
Begüm GÜRAY EFES ${ }^{1}$, Batu Can YAMAN²${ }^{2}$, Burak GÜMÜŞTAŞ ${ }^{1}$ and Murat TíRYAKI ${ }^{1}$ \\ ${ }^{1}$ Department of Operative Dentistry, Faculty of Dentistry, Istanbul University, 34390, Capa, Istanbul, Turkey \\ ${ }^{2}$ Department of Operative Dentistry, Faculty of Dentistry, Orhangazi University, Eskişehir, Turkey \\ Corresponding author, Begüm GÜRAYEFES; E-mail: begumguray@yahoo.com
}

\begin{abstract}
This in vitro study aimed to investigate the effects of glass-ionomer and flowable composite liners on the fracture resistance of Class II amalgam and composite restorations. Group 1 cavities were restored with amalgam and Group 4 cavities with nanofill composite after the application of a dentin-bonding agent. For the remaining groups, light-cured-glass-ionomer liner was used in a gingival floor proximal box (Groups 2,5) or flowable composite was used as a liner (Groups 3,6), the remainder of the cavity was restored with amalgam (Groups 2, 3) or composite (Groups 5, 6). The restorations were loaded in compression to failure. The data was analyzed using Tukey's multiple comparison test. The fracture resistance was significantly higher $(p<0.05)$ in Group 3 than in all other groups, except Group $2(p>0.05)$. Flowable composite, glass-ionomer liners increased the fracture resistance of open-sandwich Class II amalgam restorations.
\end{abstract}

Keywords: Sandwich technique, Amalgam, Composite, Fracture resistant

\section{INTRODUCTION}

Amalgam and resin composites are the preferred materials for direct restoration of posterior teeth. The durability of amalgam in large, load-bearing restorations is good-to-excellent; however, the silver-colored material has little aesthetic appeal, and its safety remains controversial. Furthermore, the material is poorly adhesive, necessitating undercuts for mechanical retention ${ }^{1)}$. Resin composite materials are increasingly used in Class II cavities because of their ability to bond to the hard tissues of the tooth ${ }^{2}$.

The durability of both amalgam and adhesive restorations seems to be closely related to the integrity of the tooth-restorative material interface. Mastication forces, occlusal habits, dietary factors, and humidity and temperature fluctuations are additional, uncontrollable factors affecting the longevity of amalgam and composite restorations ${ }^{3)}$.

The failure of dental restorations due to fractures of the tooth or the restorative material is a significant clinical problem. Fractures at the margins of the restoration have been cited as a major problem affecting marginal integrity and can lead to the failure of amalgam and resin-composite restorations ${ }^{4)}$.

Several alternative clinical techniques have been introduced to address the problems of sealing and stress in Class II cavities. Among these is the replacement of a substantial part of the resin composite with a glass ionomer cement (GIC) base in a so-called "compositelaminated GIC" or "sandwich" restoration. In a closedsandwich restoration, the cement is fully enclosed by a resin composite ${ }^{5}$. The open sandwich concept, with the

Color figures can be viewed in the online issue, which is available at J-STAGE.

Received Feb 15, 2013: Accepted Aug 6, 2013

doi:10.4012/dmj.2013-053 JOI JST.JSTAGE/dmj/2013-053
GIC cement element open to the oral environment, has been recommended for patients at high risk for caries. Such restorations are thought to help prevent caries function via good marginal sealing and continuous fluoride release $\mathrm{e}^{6,7)}$

Flowable composite resins contain less filler (60$70 \%$ by weight and $46-70 \%$ by volume) and a greater proportion of resin matrix than hybrid resins. Some manufacturers suggest the use of flowable composites as liners in areas of limited access or flow, such as irregular internal surfaces and proximal boxes of class II preparations. Flowable liners provide better adaptation; they also act as a flexible intermediate layer, which helps relieve stress during polymerization shrinkage of the restorative resin ${ }^{8,9)}$.

The use of materials with a low modulus of elasticity is generally accepted to reduce the formation of cervical gaps and marginal leakage. Flowable resin composite applied prior to the placement of restorative material may form an elastic liner and thus prevent the development of gaps at the internal margin ${ }^{10,11}$. These materials are used as the basal layer of proximal box preparations to ensure better marginal adaptation. Previous studies have examined the use of flowable materials as a buffer between the conventional composite and the inner tooth wall ${ }^{12}$. A flowable lining greatly reduces the potential for marginal void formation in Class I and Class II restorations ${ }^{13)}$. However, other studies have found that flowable composite linings do not substantially improve marginal sealing of restorations ${ }^{14,15)}$.

We hypothesized that the use of a glass ionomer or flowable composite liner could increase the quality, longevity, and fracture resistance of amalgam and composite sandwich restorations, particularly those in 
dentin-bordered cavities.

This in vitro study aimed to investigate the effects of glass ionomer and flowable composite liners on the gingival floor on the fracture strength of Class II amalgam and composite restorations.

\section{MATERIALS AND METHODS}

Forty-eight recently extracted intact human third molars, which were extracted for unrelated therapeutic reasons and showed similar coronal sizes, were used in this study (age, 24.6 \pm 3.9 years; intercuspal dimension, $5.1 \pm 1.4 \mathrm{~mm}$; mesiodistal dimension, $10.2 \pm 0.9 \mathrm{~mm}$ ). None of the study teeth showed evidence of enamel cracks and were stored in distilled water at $4^{\circ} \mathrm{C}$ for up to 3 months before this experiment. Informed consent was obtained from all subjects under a protocol approved by the appropriate institutional review board. The teeth were scaled using a scalpel and scaling instruments (Cavitron Select SPS, Dentsply, York, PA, USA) to remove residual tissue and calculus, polished with paste (Detartrine Prophy Paste, Septodont, London, UK), rinsed thoroughly with water, and examined macroscopically under magnification for defects of the enamel and dentin. The teeth were then embedded in autopolymerizing resin (Kemdent Cold Cure, Associated Dental Products Ltd., Swindon, UK) by using a split polytetrafluoroethylene mold. The teeth were suspended within the molds and liquid resin was poured to within $2 \mathrm{~mm}$ of the CEJ. Class II proximal vertical-slot cavities were prepared in the mesial faces of all teeth by using an oval-head-shape fissuretype diamond bur (S6830RL.314.014, Komet, Lemgo, Germany) in a high-speed turbine (KaVo Powertorque 646B, KaVo Dental GmbH, Biberach, Germany) with oilfree water irrigation. The cavities were approximately $4 \mathrm{~mm}$ in buccolingual width, and the gingival proximal box margin was placed approximately $1 \mathrm{~mm}$ below the cementoenamel junction (CEJ). The pulpal depth of the proximal boxes was roughly $4 \mathrm{~mm}$. No beveled edges were apparent on the cavosurface angles of the preparations. An individual not involved in the study then blindly divided the prepared specimens into 6 groups of 8 teeth.

Group 1. Each cavity was restored with amalgam (World Cap, Ivoclar, Schann, Liechtenstein). A matrix band (OptraMatrix, Ivoclar) was placed and secured with a Tofflemire matrix retainer (Water Pik, Inc., Fort Collins, CO, USA). Single-composition nongamma 2 spherical amalgam was incrementally placed, condensed, and carved to the contour of the tooth.

Group 2. The matrix band was placed and secured using a Tofflemire matrix retainer. The gingival floor of each Class II cavity was lined with a 1-mm-thick layer of glass ionomer (Ionoseal, VOCO GmbH, Cuxhaven, Germany) according to the manufacturer's instructions. The remainder of the cavity was restored with amalgam restorative material as described for Group 1.

Group 3. The matrix band was placed and secured with a Tofflemire matrix retainer. Each cavity was etched with 36\% orthophosphoric acid (Scotchbond Etchant, 3M ESPE, St. Paul, MN, USA) for $15 \mathrm{~s}$, rinsed with water for $10 \mathrm{~s}$, and gently dried. A total-etch 1-bottle adhesive (Adper Single Bond 2, 3M ESPE, St. Paul, MN, USA) was then applied twice. The solvent was removed using a gentle stream of air and cured using a lightcuring unit (Demetron II, Kerr Corporation, Orange, CA, USA) for $40 \mathrm{~s}$. A 1-mm-thick layer of flowable composite (Filtek Supreme XT Flowable, 3M ESPE, St. Paul, MN, USA) was applied to the gingival floor and cured for $60 \mathrm{~s}$. The remainder of the cavity was restored with amalgam restorative material as described for Group 1.

Group 4. The matrix band was placed and secured with a Tofflemire matrix retainer. Each cavity was treated with 36\% orthophosphoric acid (Scotchbond Etchant) for $15 \mathrm{~s}$. The cavity was then thoroughly rinsed for $10 \mathrm{~s}$ and gently dried, and total-etch 1-bottle adhesive was applied. Light curing was performed using the light-curing unit for $40 \mathrm{~s}$. The composite resin was applied (Filtek Supreme XT, 3M ESPE, St. Paul, MN, USA) in 3 increments: the first was against the gingival wall and the second against the pulpal wall, while the final increment was placed flush with the contour of the tooth. Each increment was light-cured. Immediately after filling, excess material was removed using polishing burs and polished using the disc system (OptiDisc System, Kerr Corporation, Orange, CA, USA).

Group 5. The gingival floor of each cavity was lined with glass ionomer as described for Group 2. The remainder of the cavity was then restored with Filtek Supreme XT as described for Group 4.

Group 6. The acid-etching of the cavity, adhesive application, and flowable composite liner placement were performed as described for Group 3. The remainder of the cavity was then restored with Filtek Supreme XT composite material as described for Group 4.

The experimental groups are summarized in Table 1.

All restored specimens were stored in distilled water in the dark at $37^{\circ} \mathrm{C}$ for $72 \mathrm{~h}$. The specimens were then thermo-cycled 5,000 times between $5^{\circ} \mathrm{C}$ and $55^{\circ} \mathrm{C}$ water baths, with a dwell time of $30 \mathrm{~s}$ and a transfer time of 15 s. A round diamond bur (S6801.314.014, Komet, Lemgo, Germany) in a high-speed hand piece was used to produce a small flat area in the middle of the amalgam or the marginal ridge of the composite against which to apply the loading force. The teeth were subjected to a compressive load in a universal testing machine. A smooth cylindrical head $4 \mathrm{~mm}$ in diameter was mounted in a specially constructed testing head to ensure that it came into contact with the occlusal inclines of the facial and lingual cusps. The cylindrical head came into contact with both the restoration and the cavity border.

The testing machine (UTM Autograph AG-X, Shimadzu Corp., Tokyo, Japan) was operated parallel to the long axis of the specimen at a crosshead speed of 0.5 $\mathrm{mm} / \mathrm{min}$ until the tooth fractured ${ }^{16,17)}$. The failure load of the restorations was recorded in newton and analyzed 
by one-way ANOVA and Tukey's multiple comparison test using a statistical software program (SPSS version 10.0, SPSS Inc., Chicago, IL, USA). A $p$-value of $<0.05$ was considered statistically significant.

\section{RESULTS}

The fracture resistance of the restored teeth was defined for each specimen as the amount of force applied to the occlusal surface at which fracture occurred. The means and standard deviations of the fracture load values of all groups were calculated and are shown in Table 2. The 1-way ANOVA and Tukey's multiple comparison tests revealed a significant difference among the groups.

No statistically significant differences were observed among Groups 1, 2, 4, 5, and 6 ( $p>0.05)$. The fracture resistance was significantly higher in Group 3 than in Groups 1, 4, 5, and $6(p<0.05)$ but it did not differ significantly between Groups 2 and $3(p>0.05)$.

Representative failure types for each of the groups are shown in Figs. 1 and 2. All fractures were observed at the restoration-tooth interface.

Table 1 Summary of experimental groups

\begin{tabular}{|c|c|c|c|c|c|}
\hline Groups & $\begin{array}{l}\text { Number of } \\
\text { restorations }\end{array}$ & $\begin{array}{l}\text { Sandwich } \\
\text { type }\end{array}$ & Adhesive Materials & Sandwich materials & Restorative Materials \\
\hline 1 & 8 & None & None & None & $\begin{array}{c}\text { Non gamma } 2 \text { spherical } \\
\text { amalgam } \\
\text { (World Cap, Ivoclar, } \\
\text { Schann, Liechtenstein) }\end{array}$ \\
\hline 2 & 8 & Opened & None & $\begin{array}{c}\text { Glass ionomer } \\
\text { (Ionoseal,VOCO GmbH, } \\
\text { Cuxhaven, Germany) }\end{array}$ & $\begin{array}{c}\text { Non gamma } 2 \text { spherical } \\
\text { amalgam } \\
\text { (World Cap, Ivoclar, } \\
\text { Schann, Liechtenstein) }\end{array}$ \\
\hline 3 & 8 & Opened & $\begin{array}{c}\text { Two step total etch one } \\
\text { bottle adhesive } \\
\text { (Adper Single Bond 2, 3M/ } \\
\text { ESPE, St. Paul, MN, USA) }\end{array}$ & $\begin{array}{c}\text { Flowable resin composite } \\
\text { (Filtek Supreme XT } \\
\text { Flowable, 3M/ESPE, St. } \\
\text { Paul, MN, USA) }\end{array}$ & $\begin{array}{c}\text { Non gamma } 2 \text { spherical } \\
\text { amalgam } \\
\text { (World Cap, Ivoclar, } \\
\text { Schann, Liechtenstein) }\end{array}$ \\
\hline 4 & 8 & None & $\begin{array}{c}\text { Two step total etch one } \\
\text { bottle adhesive } \\
\text { (Adper Single Bond 2, 3M/ } \\
\text { ESPE, St. Paul, MN, USA) }\end{array}$ & None & $\begin{array}{c}\text { Nanofil resin composite } \\
\text { (Filtek Supreme XT, 3M/ } \\
\text { ESPE, St. Paul, MN, USA) }\end{array}$ \\
\hline 5 & 8 & Opened & None & $\begin{array}{c}\text { Glass ionomer } \\
\text { (Ionoseal, VOCO GmbH, } \\
\text { Cuxhaven, Germany) }\end{array}$ & $\begin{array}{c}\text { Nanofil resin composite } \\
\text { (Filtek Supreme XT, 3M/ } \\
\text { ESPE, St. Paul, MN, USA) }\end{array}$ \\
\hline 6 & 8 & Opened & $\begin{array}{c}\text { Two step total etch one } \\
\text { bottle adhesive } \\
\text { (Adper Single Bond 2, 3M/ } \\
\text { ESPE, St. Paul, MN, USA) }\end{array}$ & $\begin{array}{c}\text { Flowable resin composite } \\
\text { (Filtek Supreme XT } \\
\text { Flowable, 3M/ESPE, St. } \\
\text { Paul, MN, USA) }\end{array}$ & $\begin{array}{c}\text { Nanofil resin composite } \\
\text { (Filtek Supreme XT, 3M/ } \\
\text { ESPE, St. Paul, MN, USA) }\end{array}$ \\
\hline
\end{tabular}

Table 2 Mean and standard deviation of the fracture load (newton) of each group

\begin{tabular}{lcccccc} 
& $\begin{array}{c}\text { Group1 } \\
\text { Amal. }\end{array}$ & $\begin{array}{c}\text { Group2 } \\
\text { GI/Amal. }\end{array}$ & $\begin{array}{c}\text { Group3 } \\
\text { FC/Amal. }\end{array}$ & $\begin{array}{c}\text { Group4 } \\
\text { Comp. }\end{array}$ & $\begin{array}{c}\text { Group5 } \\
\text { GI/Comp. }\end{array}$ FC/Comp. \\
\hline Mean & $2.32^{\mathrm{a}}$ & $2.76^{\mathrm{ab}}$ & $3.36^{\mathrm{b}}$ & $2.51^{\mathrm{a}}$ & $2.42^{\mathrm{a}}$ & $2.30^{\mathrm{a}}$ \\
Std Deviation & 0.80 & 0.49 & 0.22 & 0.67 & 0.59 & 0.70 \\
\hline
\end{tabular}

*Shared superscript letters indicate no significant difference

Amal.: Amalgam, GI/Amal.: Glass Ionomer/Amalgam, FC/Amal.: Flowable Composite/Amalgam, Comp.: Composite, GI/Comp.: Glass Ionomer/Composite, FC/Comp.: Flowable Composite/Composite 


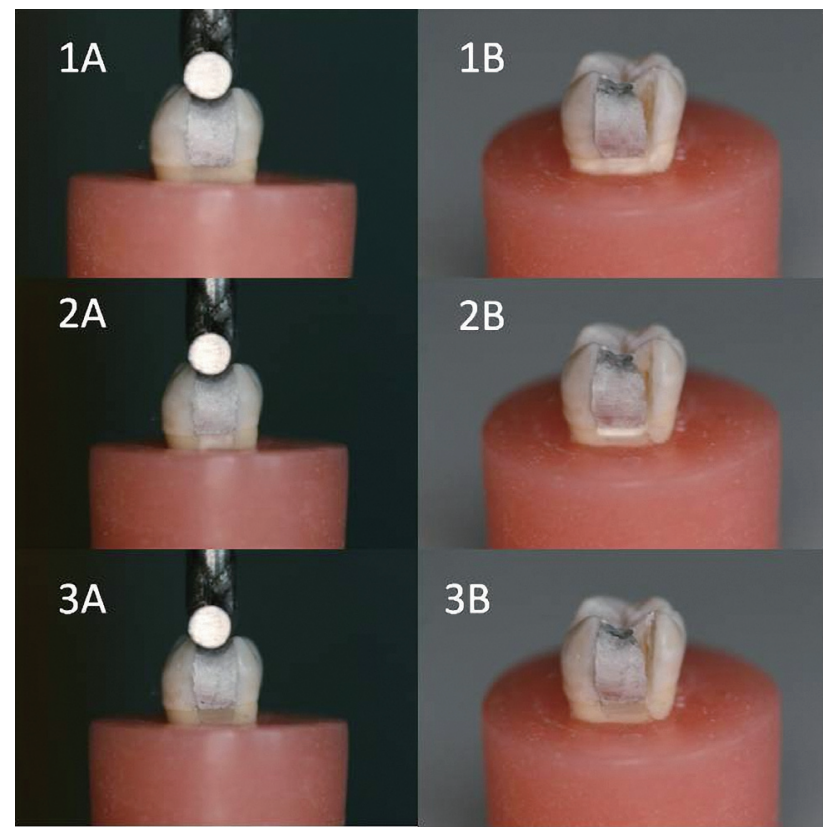

Fig. 1 Representative failure types for each of the groups (Amalgam sandwich restoration)

1A: Amalgam Restoration, 1B: Amalgam restoration after the fracture,

2A: Glass Ionomer/Amalgam Sandwich Restoration, 2B: Glass Ionomer/Amalgam Sandwich Restoration after the fracture,

3A: Flowable Composite/Amalgam Sandwich Restoration, 3B: Flowable Composite/Amalgam Sandwich Restoration after the fracture.

\section{DISCUSSION}

In this study, we investigated the effects of glass ionomer and flowable composite liners used as sandwich materials on the fracture strength of overlying amalgam or composite restorations. Failure at a higher load was accepted as indicating better strength and durability of the dental restoration.

It was necessary to use only 48 third molars teeth in 6 groups in this study due to difficulty in collecting intact human teeth. To standardize the parameters which is related morphological properties to the fracture resistance of the tooth, the teeth which showed similar coronal sizes and morphological properties, were used in this study (age, 24.6 \pm 3.9 years; intercuspal dimension, $5.1 \pm 1.4 \mathrm{~mm}$; mesiodistal dimension, $10.2 \pm 0.9 \mathrm{~mm}$ ). We described the number of specimens as described in many other study ${ }^{16,18-20)}$. During thermocycling, the specimens are exposed to constant thermal changes and stresses to accelerate aging process in vitro and to simulate intraoral influences on the bond between all test materials. Thermocycling is a valuable in vitro method to assess the results of temperature changes during mastication on dental materials in a short time. Thermocycling samples 5,000 times in water

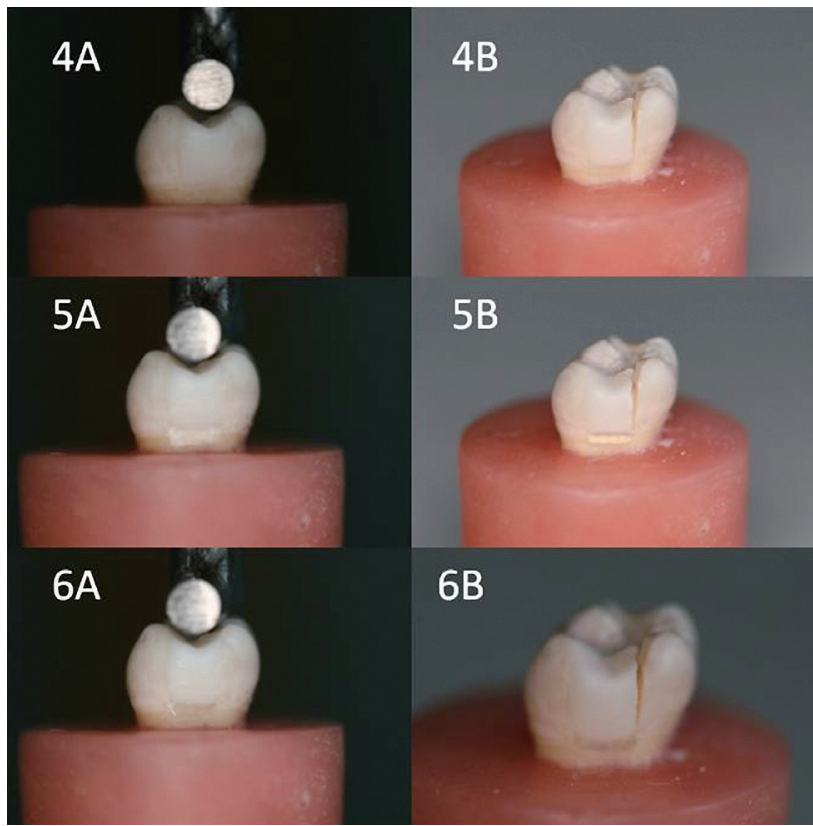

Fig. 2 Representative failure types for each of the groups (Composite resin sandwich restoration)

4A: Composite Resin Restoration, 4B: Composite Resin Restoration after the fracture,

5A: Glass Ionomer/Composite Resin Sandwich Restoration, 5B: Glass Ionomer/Composite Resin Sandwich Restoration after the fracture,

6A: Flowable Composite/Composite Resin Sandwich Restoration, 6B: Flowable Composite/Composite Resin Sandwich Restoration after the fracture.

at temperatures between 5 and $55^{\circ} \mathrm{C}$ corresponds to approximately 6 months of in vivo functioning ${ }^{21,22)}$

We had hypothesized that the use of a glass ionomer or flowable composite under an amalgam or composite sandwich restoration could provide additional fracture resistance. This hypothesis was partially rejected in light of the fracture test results.

Glass ionomer and flowable composite liners produced higher fracture resistance only in class II amalgam restorations $(3.36 \pm 0.22 \quad \mathrm{~N})$. Sandwich techniques using flowable composite or glass ionomer liners did not effectively increase the fracture resistance of composite restorations.

Concern has been expressed about the use of glass ionomer rather than flowable composite liners with amalgam in an open-sandwich technique owing to the lack of adhesion of amalgam, as opposed to resin composite, to the tooth. This lack of adhesion was thought to increase the direct transfer of occlusal stress forces to the glass-polyalkenoate material, which could possibly lead to failure ${ }^{23)}$. Micro-mechanical interlocking between amalgam and glass ionomer has been considered responsible for adhesion in amalgam restorations. It has also been shown that resin-modified glass ionomer cement may produce hybridization with 
the dentin substrate ${ }^{1)}$. However, our results demonstrated no statistically significant differences in fracture resistance between restorations prepared with glass ionomer vs. flowable composite liners under amalgam when the sandwich technique was used. The failure modes of the 2 groups were similar, which may be attributable to the elastic modulus of dentin being in the same range as the amalgam restoration material. Meanwhile, those of the glass ionomer and flowable composite liners showed similar elastic modulus.

Various studies of the effects of liners on the fracture strength of amalgam have shown that the modulus of elasticity of the liner significantly influences the resistance of the amalgam to fracture under a compressive load ${ }^{24,25)}$. These results are in agreement with those of our study. The use of a flowable composite liner under the amalgam significantly increased the fracture resistance of the restoration. On the basis of the low elastic modulus and high wettability of flowable materials relative to conventional composites, investigators conceived the idea of an "elastic wall" or "elastic bonding" and proposed to apply flowable materials as an intermediate layer ${ }^{26,27)}$. This type of intermediate layer may absorb not only the stress of shrinkage during the polymerization of the composite resins in situ but also the stress of functional loading of the restored teeth. The efficiency of the intermediate layer at absorbing stress depends on its thickness and modulus; for any given modulus, the thicker the layer, the more stress will be absorbed. Increasing the thickness of this layer also increases the volume of the material and, consequently, the extent of volumetric contraction and the corresponding contraction force; however, it also increases the absorption of contraction forces ${ }^{28)}$. Cavalcanti and Hormati showed that increasing the thickness of the base material decreased the fracture resistance of the restoration ${ }^{27,29)}$, demonstrating the importance of the thickness of the base material. Palmer et al. concluded that the fracture resistance of amalgam restorations was not affected by the presence of a $0.5-\mathrm{mm}$ thickness of lining material ${ }^{30}$. On the contrary, in our study, the addition of a lining to amalgam restorations increased their fracture resistance. This discrepancy can be explained by the greater thickness of the lining materials used in our study.

This study investigated the effect of glass ionomer liners used as sandwich materials on the fracture strength of overlying amalgam restorations, and the results showed that amalgam restorations with intermediate flowable composite $(3.36 \pm 0.22 \mathrm{~N})$ or glass ionomer liners $(2.76 \pm 0.49 \mathrm{~N})$ have greater fracture resistance. The present results contrast with those of Farah et al., who found that the mean fracture resistance was lower for amalgams supported by lowmodulus cement bases than for restorations supported by higher-modulus materials ${ }^{31)}$.

Amalgam restorations absorbed the force and transferred it to the tooth, resulting in the observed failure at the tooth-restorative material interface.
Fracture resistance of the tooth-amalgam restoration complex is higher than that of the tooth-composite restoration complex. Fractures occurred in the teeth with composite restorations when the force was dispersed through the restoration and focused at the weakest area - the composite restoration and tooth interface. In a well-bonded restoration with mechanically resistant tooth tissue, the weakest link is the toothcomposite interface ${ }^{32,33)}$.

In the current study, a sandwich technique including a flowable composite liner did not increase the fracture resistance of composite relative to composite restorations without flowable composite liners. Several other studies support this result ${ }^{34-36)}$. Ozgunaltay et al. compared the fracture resistance of Class II packable composite restorations with and without flowable liners and found no significant difference ${ }^{34)}$.

The use of flowable composite as a liner under composite restorations did not significantly improve fracture resistance over that of glass ionomer/composite restorations. The use of an intermediate layer of lowviscosity or low-elastic modulus flowable composite or glass ionomer has been recommended in order to relieve the stress of polymerization shrinkage ${ }^{9,37)}$.

Glass ionomer cements have properties that include physicochemical bonding to both enamel and dentin. The bond strength between glass ionomer and resin composite has been described as very weak; therefore, the interface between the glass ionomer and the resin can almost be considered an inadequate bonded surface. Moreover, the mechanical strength of the glass ionomer is lower than that of resin composite, resulting in poor compensation of the stress absorber ${ }^{38)}$.

Within the limitations of this study, we can conclude that flowable composite and glass ionomer materials with relatively low-viscosity could be advantageously used as liners under Class II amalgam restorations, as their lower modulus of elasticity values compared with conventional resins result in better absorption of tooth flexure forces. The physical properties of flowable composite also permit greater adaptation to tooth structure than its traditional counterpart, making it an ideal base material for improving the fracture resistance of extensive Class II amalgam restorations. However, further research concerning microleakage and alternative preparation designs is warranted.

\section{REFERENCES}

1) Cenci MS, Piva E, Potrich F, Formolo E, Demarco FF, Powers JM. Microleakage in bonded amalgam restorations using different adhesive materials. Braz Dent J 2004; 15: 13-18.

2) Geurtsen W, Schoeler J. 4-year retrospective clinical study of Class I and II composite fillings. J Dent 1997; 25: 229-232.

3) Huang MS, Li MT, Huang FM, Ding SJ. The effect of thermocycling and dentine pre-treatment on the durability of the bond between composite resin and dentine. J Oral Rehabil 2004; 31: 492-499.

4) DaCunha Mello FS, Feilzer AJ, de Gee AJ, Davidson CL. Sealing ability of eight resin bonding systems in a Class II restoration after mechanical fatiguing. Dent Mater 1997; 13: 372-376. 
5) Knibbs P. The clinical performance of a glass polyalkenoate (glass ionomer) cement used in a "sandwich" technique with a composite resin to restore class II cavities. Br Dent J 1992; 1172: 102-107.

6) Davidson CL. Glass ionomer bases under posterior composites. J Esthet Dent 1994; 6: 223-224.

7) Koubi S, Raskin A, Dejou J, About I, Tassery H, Camps J, Proust JP. Effect of dual cure composite as dentin substitute on the marginal integrity of Class II open-sandwich restorations. Oper Dent 2010; 35: 165-171.

8) Abdalla AI. Bond strength of a total-etch and two self-etch adhesives to dentin with and without intermediate flowable liner. Am J Dent 2010; 23: 157-160.

9) Olliveira LC, Duarte S Jr, Araujo CA, Abrahão A. Effect of low-elastic modulus liner and base as stress-absorbing layer in composite resin restorations. Dent Mater 2010; 26: 159169.

10) Labella R, Lambrechts $P$, Van Meerbeek B, Vanherle G. Polymerization shrinkage and elasticity of flowable composites and filled adhesives. Dent Mater 1998; 15: 128-137.

11) Ozel E, Korkmaz Y, Attar N. Influence of location of the gingival margin on the microleakage and internal voids of nanocomposites. J Contemp Dent Pract 2008; 9: 65-72.

12) Estafan D, Estafan A, Leinfelder KF. Cavity wall adaptation of resin-based composite lined with flowable composites. Am J Dent 2000; 13: 192-194.

13) Haak R, Wicht MJ, Noack MJ. Marginal and internal adaptation of extended class I restorations lined with flowable composites. J Dent 2003; 31: 231-239.

14) Chuang SF, Jin YT, Lin TS, Chang CH, García-Godoy F. Effects of lining materials on microleakage and internal voids of Class II resin-based composite restorations. Am J Dent 2003; 16: 84-90.

15) de Mattos Pimenta Vidal C, Pavan S, Briso AL, BedranRusso AK. Effects of three restorative techniques in the bond strength and nanoleakage at gingival wall of Class II restorations subjected to simulated aging. Clin Oral Investig 2012; 17: 627-633.

16) Monga P, Sharma V, Kumar S. Comparison of fracture resistance of endodontically treated teeth using different coronal restorative materials: An in vitro study. J Conserv Dent 2009; 12: 154-159.

17) Bijelic J, Garoushi S, Vallittu PK, Lassila LV. Fracture load of tooth restored with fiber post and experimental short fiber composite. Open Dent J 2011; 29: 58-65.

18) Hayashi M, Takahashi Y, Imazato S, Ebisu S. Fracture resistance of pulpless teeth restored with post-cores and crowns. Dent Mater 2006; 22: 477-485.

19) Kikuti WY, Chaves FO, Di Hipólito V, Rodrigues FP, D'Alpino $\mathrm{PH}$. Fracture resistance of teeth restored with different resinbased restorative systems. Braz Oral Res 2012; 26: 275-281.

20) Arunpraditkul S, Saengsanon S, Pakviwat W. Fracture resistance of endodontically treated teeth: three walls versus four walls of remaining coronal tooth structure. J Prosthodont 2009; 18: 49-53.

21) Baracco B, Fuentes MV, Garrido MA, González-López S, Ceballos L. Effect of thermal aging on the tensile bond strength at reduced areas of seven current adhesives.
Odontology 2012 Jul 13. DOI 10.1007/s10266-012-0073-2.

22) Gale MS, Darvell BW. Thermal cycling procedures for laboratory testing of dental restorations. J Dent 1999; 27: 8999.

23) Roberts HW, Vandewalle KS, Charlton DG, Berzins DW. Fracture resistance of amalgam/glass-polyalkenoate open sandwich Class II restorations: an in vitro study. J Dent 2008; 36: 873-877.

24) Pierpont WF, Gray SE, Hermesch CB, Hilton TJ. The effect of various bases on the fracture resistance of amalgam. Oper Dent 1994; 19: 211-216.

25) Chen RS, Liu CC, Chang MR, Lin CP. Bonded amalgam restorations: using a glass-ionomer as an adhesive liner. Oper Dent 2000; 25: 411-417.

26) Kemp-Scholte CM, Davidson CL. Marginal integrity related to bond strength and strain capacity of composite resin restorative systems. J Prosthet Dent 1990; 64: 658-664.

27) Cavalcanti AN, Mitsui FH, Ambrosano GM, Marchi GM. Influence of adhesive systems and flowable composite lining on bond strength of class II restorations submitted to thermal and mechanical stresses. J Biomed Mater Res B Appl Biomater 2007; 80: 52-58.

28) Castañeda-Espinosa JC, Pereira RA, Cavalcanti AP, Mondelli RF. Transmission of composite polymerization contraction force through a flowable composite and a resin-modified glass ionomer cement. J Appl Oral Sci 2007; 15: 495-500.

29) Hormati AA, Fuller JL. The fracture strength of amalgam overlying base materials. J Prosthet Dent 1980; 43: 52-57.

30) Palmer AE, Davis RD, Murchison DF, Cohen RB. Fracture strength of Class 2 amalgams with various cavity-lining materials. Oper Dent 1999; 24: 45-50.

31) Farah JW, Clark AE, Mohsein M, Thomas PA. Effect of cement base thicknesses on MOD amalgam restorations. J Dent Res 1983; 62: 109-111.

32) Versluis A, Douglas WH, Cross M, Sakaguchi RL. Does an incremental filling technique reduce polymerization shrinkage stresses? J Dent Res 1996; 75: 871-878.

33) Ensaff H, O'Doherty DM, Jacobsen PH. The influence of the restoration-tooth interface in light cured composite restorations: a finite element analysis. Biomaterials 2001; 22: 3097-3103.

34) Özgünaltay G, Görücü J. Fracture resistance of class II packable composite restorations with and without flowable liners. J Oral Rehabil 2005; 32: 111-115.

35) Görücü J. Fracture resistance of class II preformed ceramic insert and direct composite resin restorations. J Dent 2003; 31: 83-88.

36) Stappert CF, Att W, Gerds T, Strub JR. Fracture resistance of different partial-coverage ceramic molar restorations: An in vitro investigation. J Am Dent Assoc 2006; 137: 514-522.

37) Braga RR, Hilton TJ, Ferracane JL. Contraction stress of flowable composite materials and their efficacy as stressrelieving layers. J Am Dent Assoc 2003; 134: 721-728.

38) Arora V, Kundabala M, Parolia A, Thomas MS, Pai V. Comparison of the shear bond strength of RMGIC to a resin composite using different adhesive systems: an in vitro study. J Conserv Dent 2010; 13: 80-83. 